\title{
Welcome Notes
}

It is a great pleasure to observe how the topic of Musikvermittlung is gaining ground at the mdw - University of Music and Performing Arts Vienna. From the area of preliminary studies to its emphasis in artistic and pedagogical studies, to special initiatives at the Department of Music Education Research, Music Didactics and Elementary Music Education (IMP), Musikvermittlung is being both practiced and researched here, the latter in cooperation with the Department of Music Sociology (IMS). Further major steps forward in the implementation of Musikvermittlung in courses at our university are imminent.

Many thanks and congratulations to Axel Petri-Preis (IMP) and Sarah Chaker (IMS) for the conception and realisation of the lecture and event series in 2019/2020 and for the conversion of this format into the present publication.

\section{Barbara Gisler-Haase}

Vice Rector for Academic Affairs and Young Artists' Promotion at the mdw University of Music and Performing Arts Vienna 
It remains a desideratum to further explore the young field of Musikvermittlung academically, in empirical research as well as from the starting point of the humanities - and both approaches are necessary. So the lecture series that took place in autumn and winter 2019/20 at the mdw - University of Music and Performing Arts Vienna contributed to this target in remarkable way: we faced lectures with a wide academic range, opening onto a broad horizon.

Yet the organisers and curators, Sarah Chaker and Axel Petri-Preis, also wanted to demonstrate what Musikvermittlung feels like, showing its possibilities, exploring what it could be, and so on these evenings fascinating musicians made appearances, inspiring settings could be experienced, involvement and resonance happened.

We, the audience, not only listened to interesting lectures, but were invited to co-act with the musicians, to listen, to watch, to feel and even to taste. The lecture hall was variously transformed into a concert hall and a performance venue, with the events switching between periods of listening and understanding on the one hand, and moments of being overwhelmed and moved on the other.

This publication includes the lectures which were given - as may be expected in a book like this - but it also tries to catch the aesthetic experience and the atmosphere of the evenings.

I therefore really appreciate that this attempt is being made and I am glad that the mdw - University of Music and Performing Arts Vienna has supported this project.

\section{Peter Röble}

Head of the Department of Music Education Research, Music Didactics and Elementary Music Education at the mdw - University of Music and Performing Arts Vienna 